FEDERAL RESERVE BANK OF SAN FRANCISCO

WORKING PAPER SERIES

\title{
Specifying and Estimating New Keynesian Models with Instrument Rules and Optimal Monetary Policies
}

\author{
Richard Dennis \\ Federal Reserve Bank of San Francisco
}

January 2005

Working Paper 2004-17

http://www.frbsf.org/publications/economics/papers/2004/wp04-17bk.pdf

The views in this paper are solely the responsibility of the authors and should not be interpreted as reflecting the views of the Federal Reserve Bank of San Francisco or the Board of Governors of the Federal Reserve System. 


\title{
Specifying and Estimating New Keynesian Models with Instrument Rules and Optimal Monetary Policies*
}

\author{
Richard Dennis ${ }^{\dagger}$ \\ Federal Reserve Bank of San Francisco
}

First version: September 2004

This version: January 2005

\begin{abstract}
This paper looks at whether sticky-price New Keynesian models with microfounded inertia can usefully describe US data. We estimate a range of models, considering specifications with either internal or external consumption habits, specifications containing Taylor-type rules or an optimal discretionary rule, and specifications where inflation is driven by movements in the gap or real marginal costs. Among other results, we find that models with external habits produce very similar aggregate behavior to models with internal habits. We also find that modeling monetary policy in terms of an optimal discretionary rule describes US data as well as a forward-looking Taylor-type rule does, and that the data favor the traditional gap-based Phillips curve over specifications containing real marginal costs.

Keywords: Real Marginal Costs, Phillips Curve, Optimal Policy, Taylor Rules.
\end{abstract}

JEL Classification: E52, E58.

\footnotetext{
${ }^{*}$ I would like to thank Giovanni Olivei and seminar participants at the University of Oregon, The Nederlandsche Bank, Florida State University, and the Dynamic Macroeconomic Theory Conference, Copenhagen, for comments. I would like to thank Kirk Moore for research assistance. The views expressed in this paper do not necessarily reflect those of the Federal Reserve Bank of San Francisco or the Federal Reserve System.

${ }^{\dagger}$ Address for Correspondence: Economic Research, Mail Stop 1130, Federal Reserve Bank of San Francisco, 101 Market St, CA 94105, USA. Email: richard.dennis@sf.frb.org.
} 


\section{Introduction}

This paper estimates several popular sticky-price New Keynesian models in an effort to understand whether and under what circumstances these models can usefully describe observed outcomes. We estimate and compare specifications that contain different forms of habit formation, specifications that have either the gap or real marginal costs driving inflation, and specifications that use either optimal policymaking or a forward-looking Taylor-type rule to summarize monetary policy. Among other results, we find that the different forms of habit formation lead to very similar aggregate behavior, that optimal policymaking explains the data as well as a Taylor-type rule does, and that the data speak strongly against specifications that have real marginal costs as the driver in the Phillips curve.

New Keynesian models have been extensively used to study macroeconomic dynamics and to design and analyze monetary policy rules (Clarida, Galí, and Gertler, 1999; Taylor, 1999). They are also used to study business cycle dynamics, and the importance of various rigidities for generating these dynamics, and as a framework to explore learning behavior (Evans and Honkapohja, 2001). These models generally consist of three equations: an aggregate demand equation in the form of an IS curve, an inflation equation in the form of a Phillips curve, and a policy rule for the short-term nominal interest rate. Hybrid specifications, which have both forwardand backward-dynamics in the IS and Phillips curves, are especially popular because they are able to endogenously replicate some of the persistence present in many aggregate time series. Coupled with their simplicity and clear intuition, these hybrid models' ability to generate persistence gives them empirical credibility, lending weight to their description of how the economy responds to shocks and to their implications for how monetary policy should be formulated. ${ }^{1}$

The importance of backward-dynamics in hybrid New Keynesian models is such that there is a burgeoning literature dedicated to developing their micro-foundations. In the IS curve, backward-dynamics are typically introduced through some form of habit formation in consumption. However, there does not appear to be a consen-

\footnotetext{
${ }^{1}$ In addition to generating persistence per se, hybrid models, such as Fuhrer (2000), appear able to qualitatively replicate the hump-shaped responses known to characterize many macroeconomic variables (Blanchard, 1981).
} 
sus on whether the consumption habits should be internal or external to households. With internal habits a household's marginal utility of consumption depends on the history of its own consumption, whereas with external habits it depends on the history of other households' consumption. The appropriate specification for the IS curve depends on how habit formation is modeled. For the Phillips curve, inertia is often introduced through the assumption that some firms form naïve, or adaptive, expectations (Roberts, 1997) or that some firms set prices by indexing their price change to past inflation (Christiano, Eichenbaum, and Evans, 2004). More generally, these is debate over whether the fundamental variable driving movements in inflation should be real marginal costs (Galí and Gertler, 1999; Sbordone, 2002) or the output gap, or whether New Keynesian Phillips curve are incorrectly specified regardless of which is the driving variable (Rudd and Whelan, 2003).

While there is little consensus regarding their micro-foundations, it is widely recognized that backward-dynamics are important, if only because specifications that contain only forward-dynamics struggle when taken to the data (Ball, 1991; Fuhrer, 1997). In fact, the empirical motivation for backward-dynamics is so compelling that there is a tendency to either specify the backward-dynamics directly, setting aside the micro-foundations that produce them, or to place the backward-dynamics in the shocks. $^{2}$ The former approach makes it difficult to distinguish among alternative theories of inertia while the latter approach makes it difficult to determine whether or not the model is appropriately specified. ${ }^{3}$

To address some of these specification issues, and to examine whether models with micro-founded backward-dynamics can reasonably account for observed data, we estimate a range of micro-founded New Keynesian models for the US. Following Christiano et al., (2004), we consider an environment in which some proportion of firms are Calvo-pricing (Calvo, 1983) and the remainder undertake price indexation, arriving at a hybrid Phillips curve that has real marginal costs as the variable driving inflation. When modeling households we allow for habit formation in consumption, considering both internal habits and external habits. Whether the habit formation

\footnotetext{
${ }^{2}$ See Rotemberg and Woodford (1997) for example.

${ }^{3}$ Of course, not all of the literature has taken one of these approaches. Important exceptions include Yun (1996), Ireland (1997), Kim (2000), Fuhrer (2000), and the recent papers by Christiano et al., (2004) and Smets and Wouters (2004).
} 
is internalized or not impacts not only the IS curve (the consumption Euler equation), but also the marginal rate of substitution between consumption and leisure. Consequently, the relationship between real marginal costs and the gap is affected by how habit formation is modeled. Using the appropriate relationship between the gap and real marginal costs, we estimate and compare Phillips curves that are driven alternately by the gap or real marginal costs.

We also consider two distinct approaches to modeling monetary policy. Under one approach we close the model by assuming that monetary policy is set according to a forward-looking Taylor-type rule. Because Taylor-type rules, in various forms, have been widely studied, the estimates we obtain can be easily compared to other estimates in the literature. As an alternative to a Taylor-type rule, we also consider the possibility that monetary policy is set "optimally", but under discretion. To implement this approach, we assume that the central bank is an optimizing agent (like the other agents in the model), postulate a (quadratic) objective function for the policymaker, and estimate the parameters in the model - including those in the policy objective function - from the time-consistent equilibrium. A state-contingent decision rule for the central bank emerges in the time-consistent equilibrium, but interest centers on the estimates of the objective-function parameters because these reveal how observed outcomes are best described in terms of an optimal-policy framework.

While modeling monetary policy as the solution to a control problem has obvious appeal, there is also value in comparing the resulting model-estimates to the modelestimates obtained from the Taylor-type rule. Big differences between the parameter estimates or their respective fits to the data would lend weight to one description of policy over the other. In particular, because the forward-looking Taylor-type rule is less restrictive, such differences might suggest that optimally policymaking is incompatible with observed data. Alternatively, if the respective model-estimates and fits to the data are similar, then the estimated policy objective function informs on the policy goals that give rise to the parameters in estimated forward-looking Taylor-type rules.

In all, eight specifications are fitted to US data for the period 1982.Q1 - 2002.Q4. The equations in each specification are estimated jointly using Full Information Maximum Likelihood, where the maximum of the (log-) likelihood is located using a genetic 
algorithm. For some specifications cross-equation restrictions emerge in the loglinearized equations describing household and firm behavior. Other cross-equation restrictions arise in the rational expectations/time-consistent equilibrium. To ensure internal consistency, all relevant cross-equation restrictions were imposed during estimation; the genetic algorithm facilitates imposing these restrictions and estimating the models without taking numerical derivatives.

The remainder of this paper is structured as follows. Section 2 presents and discusses the specifications that are estimated. Section 3 describes the data on which the models are estimated, discusses how the models are estimated, and presents model-estimates first under the assumption that monetary policy is set according to an optimal discretionary rule and second under the assumption that monetary policy is set according to a forward-looking Taylor-type rule. Section 4 looks at how the models behave in response to shocks, comparing their impulse response functions to those from a structural VAR model. Using relative information statistics, Section 4 also examines how models with internal habits perform relative to models with external habits and how models that have optimal policymaking perform relative to models containing Taylor-type rules. Section 5 concludes and discusses possible extensions.

\section{Empirical Specifications}

The systems that we estimate consist of a Phillips curve, a consumption equation, and an equation summarizing monetary policy behavior. We consider consumption equations that are derived from internal habit formation and external habit formation, and allow monetary policy to be set either according to a forward-looking Taylor-type rule or according to an optimal discretionary rule. The Phillips curves, derived from Calvo-pricing and price indexation, are estimated with either the output gap or real marginal costs as the driving variable.

\subsection{Phillips Curve}

Output, $Y_{t}$, is produced by a unit measure of monopolistically competitive firms. The $j$ 'th firm faces a downward sloping demand curve given by $y_{t}^{j}=Y_{t}\left(\frac{p_{t}^{j}}{P_{t}}\right)^{-\varepsilon},(\varepsilon>1)$, where $y_{t}^{j}$ and $p_{t}^{j}$ are the $j$ 'th firm's output and price levels, respectively, and where 
the aggregate price level, $P_{t}$, is given by $P_{t}=\left[\int_{0}^{1}\left(p_{t}^{j}\right)^{1-\varepsilon} d j\right]^{\left(\frac{1}{1-\varepsilon}\right)}$. Each firm hires labor in a perfectly competitive labor market and produces using the production technology, $y_{t}^{j}=e^{u_{t}}\left(L_{t}^{j}\right)^{\kappa}, 0<\kappa<1$, where $e^{u_{t}}$ is a total factor productivity shock. Following Calvo (1983), each period a fixed proportion of firms, $1-\xi(0 \leq \xi \leq 1)$, receives a signal to re-optimize their price. Firms that receive the signal choose their price and the quantity of labor they wish to hire. Firms that do not receive the signal choose the quantity of labor they wish to hire and index their price change to last period's inflation rate.

Profits for a firm that receives the Calvo-signal (the $j$ 'th firm, say) are given by

$\Pi^{j}=E_{t} \sum_{i=0}^{\infty} \frac{\lambda_{t+i}(\beta \xi)^{i}}{\lambda_{t}}\left[\frac{p_{t+i}^{j}}{P_{t+i}}\left(\frac{p_{t+i}^{j}}{P_{t+i}}\right)^{-\varepsilon} Y_{t+i}-\frac{W_{t+i}}{P_{t+i}} L_{t+i}^{j}+\mu_{t+i}\left(e^{u_{t+i}}\left(L_{t+i}^{j}\right)^{\kappa}-y_{t+i}^{j}\right)\right]$.

Christiano et al., (2004) show that the first-order condition for optimal pricesetting combined with price indexation by non-optimizing firms, when log-linearized about the economy's nonstochastic steady state, leads to the following Phillips curve for aggregate inflation ${ }^{4}$

$$
\pi_{t}=\frac{1}{1+\beta} \pi_{t-1}+\frac{\beta}{1+\beta} E_{t} \pi_{t+1}+\frac{(1-\beta \xi)(1-\xi)}{(1+\beta) \xi} \widehat{m c}_{t}
$$

In equation (1), $\widehat{m c}_{t}$ represents real marginal costs, which, because there is no capital in production, simply equals the real wage divided by the marginal product of labor. Any profits that firms earn are returned to households (shareholders) in the form of a lump-sum dividend payment. One important feature of equation (1) is that price indexation by non-optimizing firms generates a lag of inflation in the aggregate Phillips curve. ${ }^{5}$

\subsection{Forward-looking IS Curves}

We assume that households are infinitely lived and have identical preferences. Households consume a Dixit-Stiglitz aggregate of the goods that firms produce: $C_{t}=$

\footnotetext{
${ }^{4}$ The log-linearization is about a nonstochastic steady state with an average rate of inflation, $\pi^{*}$, that is not necessarily zero.

${ }^{5}$ An alternative approach is taken by Fuhrer and Moore (1995). They employ overlapping relative real wage contracts (Buiter and Jewitt, 1981) to generate a New Keynesian Phillips curve with similar forward- and backward-dynamics.
} 
$\left[\int_{0}^{1}\left(c_{t}^{j}\right)^{\frac{\varepsilon-1}{\varepsilon}} d j\right]^{\frac{\varepsilon}{\varepsilon-1}}$. In addition to consumption, household preferences are defined over leisure, real money balances, and habit consumption. The representative household's expected lifetime utility is given by

$$
U=E_{t} \sum_{i=0}^{\infty} \beta^{i} u\left(C_{t+i}, H_{t+i}, L_{t+i}, \frac{M_{t+i}}{P_{t+i}}\right),
$$

where $H_{t}$ denotes habit consumption, $L_{t}$ denotes labor supply, and $\frac{M_{t}}{P_{t}}$ denotes real money balances; $E_{t}$ represents the mathematical expectations operator conditional upon period $t$ information and $\beta(0<\beta<1)$ is the subjective discount factor. Under one specification, we assume that households have internal habit formation, that habit consumption is given by $H_{t}=C_{t-1}^{\gamma},(0 \leq \gamma \leq 1)$, and that the instantaneous utility function takes the additively-separable form

$$
u(., ., ., .)=\frac{e^{g_{t}}\left(\frac{C_{t}}{C_{t-1}^{\gamma}}\right)^{1-\sigma}}{1-\sigma}+\frac{\left(\frac{M_{t}}{P_{t}}\right)^{1-\alpha}}{1-\alpha}-\frac{L_{t}^{1+\theta}}{1+\theta} .
$$

With internal habit formation, the household's marginal utility of consumption is increasing in the quantity of goods consumed in the previous period. The parameters, $\sigma, \alpha$, and $\theta(\sigma, \alpha, \theta>0)$ regulate the curvature of the utility function with respect to consumption (relative to habit), real money balances, and leisure, respectively, while $\gamma$ indexes the degree of habit formation. A consumption-preference shock, $g_{t}$, which is assumed to be an iid, zero mean, finite variance, random variable, also enters the instantaneous utility function.

The household budget constraint is given by

$$
C_{t}+\frac{M_{t}}{P_{t}}+\frac{B_{t}}{P_{t}}=\frac{W_{t}}{P_{t}} L_{t}+\frac{\left(1+R_{t-1}\right)}{P_{t}} B_{t-1}+\frac{M_{t-1}}{P_{t}}+\frac{\Pi_{t}}{P_{t}}
$$

where $M_{t-1}$ and $B_{t-1}$ represent the stock of money and nominal bond holdings brought into period $t, R_{t}$ is the nominal interest rate that prevails during period $t$, and $\Pi_{t}$ combines the lump-sum dividend payment that households receive from firms with transfers from the government that arise from seigniorage revenue.

The Euler equation from the household's consumption decision, when log-linearized about the economy's nonstochastic steady state, can be written as

$E_{t} \Delta \widehat{c}_{t+1}=\frac{\gamma(\sigma-1)}{[\sigma+\gamma \beta(\sigma \gamma-1-\gamma)]} E_{t}\left[\Delta \widehat{c}_{t}+\beta \Delta \widehat{c}_{t+2}+\frac{1}{\gamma(\sigma-1)}\left(R_{t}-\pi_{t+1}-\rho-g_{t}\right)\right]$, 
where $\rho=-\ln (\beta)$. Equation (5) collapses to the standard time-separable consumption Euler equation in the special case where $\gamma=0$.

An alternative formulation of the household's problem is to assume that the habit formation is external to the household (Campbell and Cochrane, 1999). With external habit formation, a household's utility is affected by the quantity that other households consume, rather than by its own past consumption. To model external habit formation we assume that habit consumption, $H_{t}$, evolves according to

$$
H_{t}=\gamma C_{t-1}
$$

where $0 \leq \gamma<1$, and that the instantaneous utility function is

$$
u(., ., ., .)=\frac{e^{g_{t}}\left(C_{t}-H_{t}\right)^{1-\sigma}}{1-\sigma}+\frac{\left(\frac{M_{t}}{P_{t}}\right)^{1-\alpha}}{1-\alpha}-\frac{L_{t}^{1+\theta}}{1+\theta} .
$$

With external habit formation, utility maximization leads to the following (loglinearized about the nonstochastic steady state) Euler equation for consumption

$$
\widehat{c}_{t}=\frac{\gamma}{1+\gamma} \widehat{c}_{t-1}+\frac{1}{1+\gamma} E_{t} \widehat{c}_{t+1}-\frac{(1-\gamma)}{\sigma(1+\gamma)}\left(R_{t}-E_{t} \pi_{t+1}-\rho-g_{t}\right) .
$$

As earlier, when $\gamma=0$ equation (8) collapses the the familiar time-separable consumption Euler equation.

\subsection{Real Marginal Costs}

The Phillips curve shown as equation (1) has real marginal costs as the variable driving movements in inflation. In traditional Keynesian models, however, it is movements in the output gap - the difference between output and potential output - that drive movements in inflation (see Hall and Taylor (1997) for example). The output gap's presence in traditional Keynesian models arises from the standard $\mathrm{AD} / \mathrm{AS}$ framework in which the capital stock is constant and nominal wages are fixed one-period ahead. When nominal wages are fixed in advance and the capital stock is constant, movements in the output gap are caused by movements in the AD schedule. If demand is unusually high, generating a positive output gap, prices rise because a lower real wage is required if firms are to profitably increase production to meet the rise in demand. In terms of the New Keynesian models derived above, the assumption that

$$
\widehat{m c}_{t}=\delta \widehat{c}_{t}+v_{t}
$$


where $v_{t}$ represents a measurement error and $\delta>0$, is not only consistent with traditional Keynesian models, but it can also be thought of as an informal way of introducing behavior similar to sticky wages into the New Keynesian model. ${ }^{6}$

More generally, and in the absence of sticky wages, the relationship between the gap and real marginal costs can be derived from the households' labor supply curve, the production technology, and the economy's resource constraint. From the production technology and the economy's resource constraint we have (the log-linear expression) $\widehat{c}_{t}=u_{t}+\kappa \widehat{l}_{t}$. In log-linear form, cost minimization leads to $\widehat{m c}_{t}=$ $\widehat{w}_{t}-u_{t}-(\kappa-1) \widehat{l}_{t}$, where $\widehat{w}_{t}$ is the real wage. From the household's labor/leisure choice, the (consumption) real wage equals the marginal rate of substitution between consumption and leisure. The marginal rate of substitution between consumption and leisure depends on whether the habit formation is internal or external to the household. When the habit formation is internal, the log-linear relationship between real marginal costs and the gap is given by

$\widehat{m c}_{t}=\left[\frac{1+\theta-\kappa}{\kappa}+\sigma+\beta \gamma(\sigma \gamma-1-\gamma)\right] \widehat{c}_{t}-\gamma(\sigma-1)\left(\widehat{c}_{t-1}+\beta E_{t} \widehat{c}_{t+1}\right)-\left(\frac{1+\theta}{\kappa}\right) u_{t}-g_{t}$,

whereas when the habit formation is external, real marginal costs and the output gap are related according to

$$
\widehat{m c}_{t}=\left(\frac{1+\theta-\kappa}{\kappa}+\frac{\sigma}{1-\gamma}\right) \widehat{c}_{t}-\frac{\sigma \gamma}{1-\gamma} \widehat{c}_{t-1}-\left(\frac{1+\theta}{\kappa}\right) u_{t}-g_{t} .
$$

Note that in the special case where $\gamma=0$, and there is no habit formation, equations (10) and (11) simplify to

$$
\widehat{m c}_{t}=\left(\frac{1+\theta-\kappa}{\kappa}+\sigma\right) \widehat{c}_{t}-\left(\frac{1+\theta}{\kappa}\right) u_{t}-g_{t},
$$

which is in the form of equation (9) with $\delta=\frac{1+\theta-\kappa}{\kappa}+\sigma$ and $v_{t}=-\left(\frac{1+\theta}{\kappa}\right) u_{t}-g_{t}$. More generally, with flexible wages and some form of habit formation, lagged consumption (and expected future consumption where the habit formation is internal) influences real wages and real marginal costs because it alters the marginal rate of substitution between consumption and leisure. Hence, an increase in last period's consumption

\footnotetext{
${ }^{6}$ More generally, one could formalize the nominal wage rigidity by assuming that labor is a differentiated product, that households are monopolistic suppliers of their labor service, and then introduce Calvo-pricing over wage setting (Erceg et al., 2000).
} 
level raises the marginal utility of consumption, inducing households to substitute from leisure to consumption. The resulting increase in aggregate labor supply lowers the real wage and real marginal costs.

Equations (10) and (11) also make clear that the demand shock, $g_{t}$, and the technology shock, $u_{t}$, both affect real marginal costs. ${ }^{7}$ Consequently, when either of these specifications is substituted into equation (1) the disturbance term in the resulting Phillips curve is a linear combination of these two structural shocks. If the Phillips curve is estimated in isolation, then these two shocks cannot be separately identified, even if they are assumed to be independent of each other. It is also worth noting that the demand shock enters both the IS curve and the Phillips curve, which makes it possible that the decline in the conditional volatility of inflation and output experienced by the US since the mid-1980s (Sims and Zha, 2001; Dennis, 2004) may be due purely to a drop in the variance of demand shocks.

Unfortunately, for the gap specifications, $\delta$, in equation (9), cannot be identified separately from the Calvo-pricing parameter, $\xi$. This lack of identification occurs because the single reduced-form coefficient on $\widehat{c}_{t}$, that arises when equation (9) is substituted into equation (1), cannot identify two structural parameters. However, because $\xi$ is central to the New Keynesian framework, and because whether it is the gap or real marginal costs that should enter the Phillips curve is a bone of contention in the literature, we set $\delta=1$ and estimate $\xi$. Further, in the real marginal cost specifications the (inverse of the) elasticity of labor supply with respect to the real wage, $\theta$, and labor's share of output, $\kappa$, are (jointly) only weakly identified, making it difficult to estimate them precisely. Employing Bayesian methods, Smets and Wouters (2003) find $\theta$ to be about 0.8 and we use their estimate in what follows. We set $\kappa$, labor's share of output, equal to 0.64 .

\subsection{Monetary Policy}

To close the model, we require an equation describing the behavior of the central bank. Because households and firms are optimizing agents it is natural to treat the

\footnotetext{
${ }^{7}$ These shocks are present because the linearization is around the economy's nonstochastic steady state. If we had linearized about the economy's flex-price equilibrium instead (Amato and Laubach, 2004), then both shocks would cancel in the linearization and the Phillips curve would be stochastically singular.
} 
central bank as an optimizing agent also. ${ }^{8}$ We assume, then, that the central bank chooses the short-term nominal interest rate, $R_{t}$, to minimize

$$
\operatorname{Loss}(t, \infty)=E_{t} \sum_{j=0}^{\infty} \beta^{j}\left[\left(\pi_{t+j}-\pi^{*}\right)^{2}+\lambda \widehat{c}_{t+j}^{2}+\nu\left(\Delta R_{t+j}\right)^{2}\right], \lambda, \nu \geq 0,
$$

subject to constraints that are dictated by the behavior of households and firms. This policy objective function allows for an inflation stabilization objective, a gap stabilization objective, and an interest rate smoothing objective. In the inflation stabilization term, $\pi^{*}$ represents the central bank's implicit inflation target. We assume that monetary policy is set with discretion. When estimating the models, we allow $\lambda, \nu$, and $\pi^{*}$ to be estimated freely, subject only to non-negativity constraints on $\lambda$ and $\nu .^{9}$

As an alternative to optimal policymaking, we also consider the possibility that monetary policy may be set according to an instrument rule, such as a forward-looking Taylor-type rule. The specification that we consider is given by

$$
R_{t}=\bar{R}+\left(1-\phi_{3}\right)\left[\phi_{1} E_{t} \pi_{t+1}+\phi_{2} \widehat{c}_{t-1}\right]+\phi_{3} R_{t-1}+\epsilon_{t},
$$

where $\bar{R}=\left(1-\phi_{3}\right) \rho+\left[1-\left(1-\phi_{3}\right) \phi_{1}-\phi_{3}\right] \pi^{*}$. The rule assumes that the central bank responds with inertia to future expected inflation and to the state of the business cycle, and is closely related to the specification studied by Clarida, Galí, and Gertler (2000). Expected future inflation rather than current or lagged inflation enters the policy rule to reflect the fact that central banks consider the future evolution of the economy when setting monetary policy.

Note that if monetary policy is set optimally, then $\phi_{1}, \phi_{2}$, and $\phi_{3}$ are functions of the parameters in the policy objective function and of the optimization constraints

\footnotetext{
${ }^{8}$ Chow (1981) looks at how objective function parameters can be estimated in a linear-quadratic framework without rational expectations; Salemi (1995) provides an application. Söderlind (1999) describes and implements an approach to estimate objective function parameters in a linear-quadratic model with rational expectations, under the assumption that the policymaker can precommit. Dennis (2004) looks at identification and estimating of objective function parameters in forward-looking models, focusing on the case where policy is set with discretion.

${ }^{9}$ While equation (13) has not been derived from a second-order approximation to the household's utility function, the analysis in Woodford (2003, chapter 6) suggests that such an approximation would lead to a similar specification. If a second-order approximation of the household's utility function were used to derive the policy objective function, then the parameters $\lambda, \nu$, and $\pi^{*}$ would be functions of utility and technology parameters. Justification for freely estimating $\lambda, \nu$, and $\pi^{*}$ might then come from the assumption that a Rogoff (1985) optimally conservative central banker who has preferences that differ from the representative household - has been appointed.
} 
and cannot be considered structural. Note, also, that if equation (14) were estimated in isolation, then $\pi^{*}$ and $\rho$ cannot be separately identified. We are able to separately identify and estimate $\pi^{*}$ and $\rho$ by estimating the model as a system, achieving identification from cross-equation restrictions.

\section{$3 \quad$ Model Estimates}

The derivations in the previous section generate several interesting empirical specifications. The Phillips curve (equation 1) may depend on the gap (equation 9) or on real marginal costs (equations 10 or 11), the consumption Euler equation may reflect either internal (equation 5) or external habit formation (equation 8), and monetary policy may be set according to either an optimal discretionary rule (to minimize equation 13) or to a forward-looking Taylor-type rule (equation 14). We estimate all specifications using US data spanning 1982.Q1 - 2002.Q4, which excludes the period of non-borrowed reserves targeting that occurred in the early 1980s, but otherwise captures the time during which Volcker and Greenspan have been Federal Reserve chairman. Dennis (2003) finds that gap-based New Keynesian models perform slightly better when estimated using the federal funds rate rather than the three-month T-bill rate, and when estimated using real consumption rather than real GDP. Building on those findings, we use the quarterly average of the federal funds rate to represent $R_{t}$, use $100 \times \ln \left(C_{t} / C_{t}^{T}\right)$, to measure the consumption gap, $\widehat{c}_{t}$, where $C_{t}$ is real consumption per labor force member and where $C_{t}^{T}$ is a measure of trend $C_{t}$ (constructed using the Hodrick-Prescott filter), and use $400 \times \ln \left(P_{t} / P_{t-1}\right)$, where $P_{t}$ is the PCE price index, to measure inflation, $\pi_{t}$.

Let the vector of parameters to be estimated be denoted by $\boldsymbol{\Gamma}$. When solved for its time-consistent equilibrium (for the time-consistent-policy models) or its rational expectations equilibrium (for the Taylor-type rule models) each specification can be written as $^{10}$

$$
\mathbf{z}_{t}=\mathbf{h}+\mathbf{H}_{1} \mathbf{z}_{t-1}+\mathbf{H}_{2} \mathbf{v}_{t}
$$

where $\mathbf{z}_{t}=\left[\begin{array}{lll}\pi_{t} & \widehat{c}_{t} & R_{t}\end{array}\right]^{\prime}$ and $\mathbf{v}_{t}=\left[\begin{array}{lll}u_{t} & g_{t} & \varepsilon_{t}\end{array}\right]^{\prime}$ and $\mathbf{h}, \mathbf{H}_{1}$, and $\mathbf{H}_{2}$ are each functions of $\boldsymbol{\Gamma}$. By construction the spectral radius of $\mathbf{H}_{1}$ is less than one and

\footnotetext{
${ }^{10}$ See Dennis (2004) to see how this is achieved for the time-consistent-policy models.
} 
the system is stationary. Assuming that the shocks are normally distributed with variance-covariance matrix $\boldsymbol{\Omega}$, the concentrated log-likelihood function for the system is given by

$$
\log L_{c}\left(\Gamma ;\left\{\mathbf{z}_{t}\right\}_{2}^{T} \mid \mathbf{z}_{1}\right) \propto(T-1) \ln \left[\left|\left(\mathbf{H}_{2}\right)^{-1}\right|\right]-\frac{(T-1)}{2} \ln (|\widehat{\boldsymbol{\Omega}}|)
$$

where

$$
\widehat{\boldsymbol{\Omega}}(\Gamma)=\sum_{t=2}^{T} \frac{\left[\mathbf{H}_{2}^{-1}\left(\mathbf{z}_{t}-\mathbf{h}-\mathbf{H}_{1} \mathbf{z}_{t-1}\right)\right]\left[\mathbf{H}_{2}^{-1}\left(\mathbf{z}_{t}-\mathbf{h}-\mathbf{H}_{1} \mathbf{z}_{t-1}\right)\right]^{\prime}}{T-1} .
$$

To maximize the log-likelihood function the genetic algorithm described in Duffy and McNelis (2001) was used with a population of 2000 initial candidate solutions. The candidate solutions were drawn from a multivariate uniform distribution with the bounds on the distribution determined to ensure that the model had a unique stable equilibrium. The genetic algorithm was allowed to run for a maximum of 3000 generations or until each of the candidate solutions was identical to 5 decimal places. ${ }^{11}$ At that stage, the best candidate solution was used to initialize the BFGS algorithm. Once the BFGS algorithm had converged the standard errors for the parameter estimates were determined from the inverted Hessian evaluated at the maximum.

Section 3.1 presents estimates for specifications where monetary policy is set according to an optimal discretionary rule; section 3.2 presents estimates for specifications where monetary policy is set according to the forward-looking Taylor-type rule.

\subsection{Estimates with Optimal Policy}

With monetary policy set according to an optimal discretionary rule, the parameters to be estimated are $\Gamma=\left\{\rho, \xi, \frac{1}{\sigma}, \gamma, \pi^{*}, \lambda, \nu\right\}$, which consists of the parameters in the consumption and inflation equations and those in the policy objective function. For the specifications where inflation depends on real marginal costs, $\theta$ is also a factor.

\footnotetext{
${ }^{11}$ Advantages to using a genetic algorithm are that it does not require taking any derivatives and, by sampling over the entire admissible parameter space, it helps to ensure that a global maximum of the likelihood function is obtained. A disadvantage is that the genetic algorithm is generally much slower to converge than quasi-Newton methods.
} 
However, as noted earlier, because $\theta$ and $\kappa$ are difficult to identify ${ }^{12}$, we do not estimate them, but set them to 0.80 and 0.64 , respectively.

During estimation, all relevant parameter restrictions are imposed and the results are shown in Table 1; for parameters that are subject to inequality constraints the significance levels shown are for one-sided hypothesis tests.

\begin{tabular}{|c|c|c|c|c|}
\hline & \multicolumn{2}{|c|}{ Internal habit } & \multicolumn{2}{|c|}{ External habit } \\
\hline Parameter & Gap & Marginal costs & Gap & Marginal costs \\
\hline$\rho$ & $2.24^{\ddagger}$ & 1.31 & $2.74^{\dagger \dagger}$ & $2.36^{\ddagger}$ \\
\hline$\gamma$ & $0.88^{\dagger \dagger}$ & $0.84^{\dagger \dagger}$ & $0.86^{\dagger \dagger}$ & $0.84^{\dagger \dagger}$ \\
\hline $10 \times \frac{1}{\sigma}$ & 0.01 & 0.003 & 0.15 & 0.06 \\
\hline$\xi$ & $0.78^{\dagger \dagger}$ & $0.97^{\dagger \dagger}$ & $0.78^{\dagger \dagger}$ & $0.97^{\dagger \dagger}$ \\
\hline$\pi^{*}$ & $2.61^{\ddagger}$ & 1.86 & $2.79^{\dagger \dagger}$ & $2.40^{\ddagger}$ \\
\hline$\lambda$ & 0.001 & 12.64 & 0.006 & 11.24 \\
\hline$\nu$ & $2.13^{\ddagger}$ & $1.87^{\dagger}$ & $2.86^{\dagger}$ & $1.87^{\dagger}$ \\
\hline$-L_{c}$ & 251.74 & 253.59 & 252.31 & 253.66 \\
\hline & $\begin{array}{l}\mp \dagger \text { indice } \\
\ddagger \text { indica } \\
\text { indicat }\end{array}$ & $\begin{array}{l}\text { es significance a } \\
\text { es significance at } \\
\text { s significance at }\end{array}$ & $\begin{array}{l}\text { the } 1 \% \\
\text { the } 5 \% \\
\text { he } 10 \%\end{array}$ & $\begin{array}{l}\text { evel } \\
\text { evel } \\
\text { evel }\end{array}$ \\
\hline
\end{tabular}

Table 1 makes clear that the parameter estimates are not very sensitive to whether the habit formation is assumed to be internal or external, but that some parameter estimates are sensitive to whether the Phillips curve depends on the gap or on real marginal costs. Looking at the results for the equilibrium real interest rate, the estimates of $\rho$ range between 2.74 and 1.31 percent, with the latter value imprecisely estimated; the middle two estimates are both about 2.30 percent. An estimate of $\rho$ equal to 2.30 percent implies that the stochastic discount factor, $\beta$, is equal to 0.994 , which is very similar to the value of 0.99 that is widely used in quarterly New Keynesian models.

Estimates of the internal-habit and external-habit-formation parameters range from 0.84 to 0.88 , implying considerable inertia in consumption; these estimates are all significantly different from zero. A wide range of estimates of $\gamma$ are available in the literature. Assuming internal habits, Christiano et al., (2004) estimate $\gamma$ to be 0.63, Edge, Laubach, and Williams (2003) estimate $\gamma$ to be 0.64, Boldrin, Christiano,

\footnotetext{
${ }^{12}$ Experiments show that the estimates of the remaining model parameters are very robust to the choice of $\theta$ and $\kappa$, and that changing these parameters has very little effect on the value of the likelihood function, which is consistent them being only weakly identified by the data.
} 
and Fisher (2001) estimate $\gamma$ to be 0.73 , Fuhrer (2000) estimates $\gamma$ equal to 0.80 and 0.90 using FIML and GMM, respectively, and Giannoni and Woodford (2003) estimate $\gamma$ to be 1.00. Assuming external habits, Smets and Wouters (2003) estimate $\gamma$ to be 0.54, while the results in Smets (2003) imply that $\gamma$ equals 0.79. Calibration exercises, based on either internal or external habit formation, often set $\gamma$ to 0.80 (McCallum and Nelson, 1999).

The curvature of the utility function with respect to consumption relative to habit, $\frac{1}{\sigma}$, is estimated to be between 0.015 and 0.0003, similar to Cho and Moreno (2004). These estimates are imprecise but suggest that households are unwilling to substitute consumption through time, confirming the findings in Hall (1988) and Campbell and Mankiw (1989). ${ }^{13}$ Other estimates in the literature are based on models that either preclude consumption-habits (Yun, 1996; Ireland, 1996; Kim, 2000; and Rotemberg and Woodford, 1997), and/or that assume consumption is predetermined two quarters in advance (Rotemberg and Woodford, 1997; Amato and Laubach, 2003). Fuhrer (2000), however, estimates $\frac{1}{\sigma}$ to be between 0.08 and 0.16 , somewhat higher than the estimates in Table 1.

Perhaps unsurprisingly, the estimates of the Calvo-pricing parameter, $\xi$, are found to be highly sensitive to whether the gap or real marginal costs enters the Phillips curve. When the variable driving movements in inflation is the gap $\xi$ is estimated to be 0.78 , indicating that about 22 percent of firms re-optimize their price each quarter. This estimate of $\xi$ is consistent with Galí and Gertler (1999), who find $\xi$ to be between 0.83 and 0.92 , and with Dennis (2003), who estimates $\xi$ to be between 0.78 and 0.92 , depending on how the gap is measured, but slightly higher than the estimates in Sbordone (2002) who finds a reasonable range for $\xi$ to be $0.63-0.72$. However, when it is real marginal costs that drives movements in inflation, the picture becomes very different; the estimates of $\xi$ rise to about 0.97 . Larger values of $\xi$ imply greater price stickiness and mean that inflation is less responsive to movements in real marginal costs. Because the key difference between the real marginal cost specifications and the gap specifications is the presence of lagged and leaded consumption in the real marginal cost specifications, this suggests that the larger estimates of $\xi$ are an adverse

\footnotetext{
${ }^{13}$ The intertemporal elasticity of substitution differs from $\frac{1}{\sigma}$, equaling $[\sigma+\gamma \beta(\sigma \gamma-1-\gamma)]^{-1}$ and $\frac{(1-\gamma)}{\sigma(1+\gamma)}$ for internal habits and external habits, respectively. For admissible parameter values, these formulae imply that the intertemporal elasticity of substution is smaller than $\frac{1}{\sigma}$.
} 
reaction to these terms, rather than an estimate of price stickiness per se.

Turning to the policy regime parameters, the estimates of the implicit inflation target vary between 1.86 percent and 2.79 percent. The estimates of $\pi^{*}$ tend to be slightly smaller for the internal habit formation specifications than for the external habit formation specifications, but do not depend in any obvious way on whether the gap or real marginal costs that enters the Phillips curve. The $\pi^{*}$-estimates in Table 1 are similar to those obtained by Favero and Rovelli (2003) and Dennis (2004), who estimate $\pi^{*}$ to be 2.63 percent and 2.43 percent, respectively. Depending on how the gap is measured, Dennis (2003) obtains estimates of $\pi^{*}$ that vary between 2.30 percent and 2.72 percent. Elsewhere in the literature, by using the sample average of the real interest rate as a measure of the equilibrium real interest rate, Clarida et al., (2000) estimate $\pi^{*}$ to be between 3.47 percent and 4.52 percent, depending on how the gap and inflation are measured, for the Volcker-Greenspan period (see their Table III).

Looking now at the relative weight policymakers place on stabilizing the gap, $\lambda$, Table 1 shows that the estimates of $\lambda$ are very sensitive to how the Phillips curve is specified. For the gap-based specifications, estimates of $\lambda$ are very small, but they rise sharply to 12.64 and 11.24 when inflation responds to real marginal costs; for each specification $\lambda$ is statistically insignificant. The fact that the estimates of $\lambda$ are highly sensitive to whether inflation responds to the gap or to real marginal costs is striking. The larger point estimates of $\lambda$, by damping movements in the gap, work with the high estimates of $\xi$ to mitigate the effect lagged and leaded consumption have on inflation through their effect on real marginal costs. Interestingly, low estimates of $\lambda$ are consistent with the literature on second-order utility approximations (see Amato and Laubach, 2004, inter alia), but not with the literature on flexible inflation targeting. ${ }^{14}$

Finally, the interest rate smoothing parameter, $\nu$, is generally found to be numerically large and statistically significant; estimates range from 1.87 to 2.86 . These estimates are consistent with the results in Söderlind, Söderström, Vredin (2003), Collins and Siklos (2001), Castelnuovo and Surico (2004), and Dennis (2003, 2004),

\footnotetext{
${ }^{14}$ We do not wish to push this point too far, however, because the literature using second-order welfare approximations would typically log-linearize the Euler equations and the utility function about the economy's flexible price equilibrium, not about its nonstochastic steady state.
} 
but contrast with the estimates in Favero and Rovelli (2003).

\subsection{Estimates with Taylor-type Rule}

The estimates presented in Table 1 are based on the assumption that an optimal discretionary policy rule has been implemented over the sample period. While this assumption allows us to estimate the parameters in the central bank's policy objective function, it is also interesting and desirable to consider the case where monetary policy is set according to a Taylor-type rule. This is especially so because Taylor-type rules are often used to characterize actual policymaking, and because, if it is incorrect, the assumption that policy is set optimally may distort the model estimates. One might think that such a distortion could account for the low estimates of $\frac{1}{\sigma}$, and for the unusually high estimates of $\xi$ and $\lambda$ obtained when the Phillips curve depends on real marginal costs (see Table 1 ).

Table 2 shows the model estimates under the assumption that monetary policy is set according to the forward-looking Taylor-type rule, equation (14).

\begin{tabular}{|c|c|c|c|c|}
\hline \multicolumn{5}{|c|}{ Table 2: Estimates with Taylor-Type Rule } \\
\hline & \multicolumn{2}{|c|}{ Internal habit } & \multicolumn{2}{|c|}{ External habit } \\
\hline Parameter & Gap & Marginal costs & Gap & Marginal costs \\
\hline$\rho$ & $2.83^{\dagger \dagger}$ & $2.56^{\dagger \dagger}$ & $2.83^{\dagger \dagger}$ & $2.58^{\dagger \dagger}$ \\
\hline$\gamma$ & $0.92^{\dagger \dagger}$ & $0.84^{\dagger \dagger}$ & $0.87^{\dagger \dagger}$ & $0.84^{\dagger \dagger}$ \\
\hline $10 \times \frac{1}{\sigma}$ & 0.01 & 0.005 & 0.29 & 0.13 \\
\hline$\xi^{\circ}$ & $0.76^{\dagger \dagger}$ & $0.97^{\dagger \dagger}$ & $0.76^{\dagger \dagger}$ & $0.96^{\dagger \dagger}$ \\
\hline$\pi^{*}$ & $3.15^{\dagger \dagger}$ & $2.94^{\dagger \dagger}$ & $3.18^{\dagger \dagger}$ & $2.94^{\dagger \dagger}$ \\
\hline$\phi_{1}$ & $2.80^{\dagger \dagger}$ & $3.09^{\dagger \dagger}$ & $2.79^{\dagger \dagger}$ & $3.09^{\dagger \dagger}$ \\
\hline$\phi_{2}$ & 2.02 & $2.95^{\ddagger}$ & 2.15 & $2.98^{\ddagger}$ \\
\hline$\phi_{3}$ & $0.91^{\dagger \dagger}$ & $0.91^{\dagger \dagger}$ & $0.91^{\dagger \dagger}$ & $0.91^{\dagger \dagger}$ \\
\hline$-L_{c}$ & 251.29 & 253.32 & 251.83 & 253.33 \\
\hline & $\begin{array}{l}\text { indica } \\
\text { indicat } \\
\text { indicat }\end{array}$ & $\begin{array}{l}\text { es significance a } \\
\text { s significance a } \\
\text { s significance at }\end{array}$ & $\begin{array}{l}\text { the } 1 \% \\
\text { the } 5 \% \\
\text { he } 10 \%\end{array}$ & $\begin{array}{l}\text { evel } \\
\text { evel } \\
\text { evel }\end{array}$ \\
\hline
\end{tabular}

Setting aside the policy rule parameters, it is clear from Table 2 that the estimates of the remaining parameters are generally very similar to those presented in Table 1. Across specifications, the internal habit formation parameter varies between 0.84 and 0.92, compared to between 0.84 and 0.88 in Table 1 . Similarly, with external habits the estimates of $\gamma$ are about 0.85 in both tables. Closely comparable estimates of 
the Calvo-pricing parameter are also obtained. When the Phillips curve depends on the gap $\xi$ is about 0.76 , rising to about 0.97 for the real marginal cost specifications, similar to Table 1. Thus the finding that inflation is sensitive to movements in the gap, but insensitive to movements in real marginal costs is an empirical feature that is robust to this change in how monetary policy is formulated. Also robust to this change in the policy formation process is the estimated magnitude of $\frac{1}{\sigma}$. The estimates of $\frac{1}{\sigma}$ in Table 2 are very similar to those in Table 1, demonstrating that the small estimates of $\frac{1}{\sigma}$ are not due to distortions caused by the assumption that policymakers are optimizing agents.

We also find that the estimates of the policy rule feedback coefficients obtained in Table 2 are consistent with the estimates of $\lambda$ and $\nu$ obtained in Table 1. Specifically, the estimates of $\phi_{3}$ are large and statistically significant, which is consistent with interest rate smoothing being a significant goal in the central bank's policy objective function. The coefficient on the lagged nominal interest rate in the rule can be associated with interest rate smoothing in this environment because the lagged interest rate only enters the system as a state variable if interest rate smoothing occurs. It also appears that the magnitude of $\phi_{2}$, the coefficient on the gap in the policy rule, is associated with the magnitude of $\lambda$ in the policy objective function. The larger estimates of $\lambda$ in the real-marginal-cost specifications (see Table 1) manifest themselves in the form of larger feedback coefficients on the gap in the policy rules.

One area where the estimates in Tables 1 and 2 differ is the implicit inflation target, $\pi^{*}$. When we assumed that monetary policy was set optimally the estimates of $\pi^{*}$ were between 1.86 percent and 2.79 percent, but with the forward-looking Taylor-type rule $\pi^{*}$ now varies from 2.94 percent to 3.18 percent. Interestingly, with internal habits and the Phillips curve depending of real marginal costs, $\rho$ and $\pi^{*}$ are more precisely estimated when policy is summarized by a Taylor-type rule than when summarized by an optimal discretionary rule.

Overall, the parameters estimates in Table 2 reinforce those in Table 1 . In fact, as shown below, specifications with optimal policymaking fit the data as well as or slightly better than their counterparts containing forward-looking Taylor-type rules, implying that discretionary policymaking is an assumption that is not obviously contradicted by the data. 


\section{How do the Models Behave in Response to Shocks?}

The previous section discussed the different specifications in terms of their parameter estimates. This led to a number of interesting findings. For instance, the estimates suggest that household consumption decisions are relatively insensitive to the interest rate, or, put another way, that a very high real interest rate would be required to induce households to defer even a small proportion of their consumption. Although the estimates of $\frac{1}{\sigma}$ (and hence the intertemporal elasticity of substitution) are slightly higher with external habits, the estimates do not appear to depend on how the Phillips curve is specified on how monetary policy is formulated. Tables 1 and 2 also reveal implausibly high degrees of price inertia when the Phillips curve contains real marginal costs. In contrast, estimates of $\xi$ that are consistent with the literature are obtained when inflation responds to the gap.

Turning from the parameter estimates, in this section we focus on the behavior implied by the models, looking at their predicted behavior in response to shocks. We also assess the various models along a number of dimensions. First, we assess the models in terms of their overall ability to describe the data. Second, we explore whether internal habits or external habits best describes the data. Third, we investigate whether having inflation respond to the gap, rather than to real marginal costs, not only produces parameter estimates that are more plausible, but also performs better empirically. Finally, we examine the extent to which having monetary policy set according to an optimal discretionary rule is consistent with observed outcomes.

Unfortunately, because the different modeling assumptions are non-nested, direct testing methods cannot be used to discriminate between them. Instead, we exploit the fact that each model has a reduced form equilibrium that is encompassed by a Vector AutoRegressive (VAR) model. Using this VAR to capture the general features of the data we are able to assess the (over identifying) restrictions implied by each specification and indirectly compare the non-nested models. 


\subsection{Dynamic Properties}

When solved for their time-consistent or rational-expectations equilibrium, each of the models can be written as

$$
\mathbf{D}_{0} \mathbf{p}_{t}=\mathbf{d}+\mathbf{D}_{1} \mathbf{p}_{t-1}+\mathbf{s}_{t}
$$

where $\mathbf{p}_{t}=\left[\begin{array}{lll}\pi_{t} & \widehat{c}_{t} & R_{t}\end{array}\right]^{\prime}$, and where $\mathbf{s}_{t}=\left[\begin{array}{lll}u_{t} & g_{t} & \epsilon_{t}\end{array}\right]^{\prime}$ is a mean-zero $i i d$ process with variance-covariance matrix $\boldsymbol{\Omega}$. The theories used to derive the models produce restrictions on $\mathbf{d}, \mathbf{D}_{1}$, and $\mathbf{D}_{0}$. Because these restrictions make equation (17) a special case of a VAR process, a VAR model provides an encompassing framework within which the different specifications can be assessed. Of course, only overidentifying restrictions put restrictions on the model's reduced form, precluding tests for individual restrictions. However, by comparing the impulse response functions generated by the New Keynesian models to those from the VAR dimensions along which the New Keynesian models fail to adequately reflect the data can be isolated.

To generate impulse response functions for "demand" and "supply" shocks a recursive identification scheme is applied to a VAR model that has inflation ordered first and the federal funds rate ordered last. ${ }^{15}$ However, the impulse responses from the New Keynesian models cannot be directly compared to those from the VAR because the New Keynesian models are not recursive. To adjust for this and to ensure that a valid comparison is made, we identify the "shocks" to the New Keynesian models by placing the variables in the same order as the VAR and by imposing the same recursive identification scheme. To be precise, we take equation (17), which describes the equilibrium behavior of the New Keynesian models, and premultiply it by $\mathbf{D}_{0}^{-1}$ giving

$$
\mathbf{p}_{t}=\mathbf{k}+\mathbf{K}_{1} \mathbf{p}_{t-1}+\boldsymbol{\omega}_{t}
$$

where $\boldsymbol{\omega}_{t} \sim \operatorname{iid}\left[\mathbf{0}, \mathbf{D}_{0}^{-1} \boldsymbol{\Omega} \mathbf{D}_{0}^{\prime-1}\right] . \quad$ Let $\mathbf{M}_{0}^{-1} \mathbf{M}_{0}^{\prime-1}=\mathbf{D}_{0}^{-1} \boldsymbol{\Omega} \mathbf{D}_{0}^{\prime-1}$, where $\mathbf{M}_{0}^{\prime-1}$ is an upper triangular matrix constructed using a Choleski decomposition, then premulti-

\footnotetext{
${ }^{15}$ We use a $\operatorname{VAR}(2)$ model rather than a $\operatorname{VAR}(1)$ model as the benchmark in order to see whether the New Keynesian models are missing any higher order dynamics. We also impose a single over identifying restriction on the VAR model: that the coefficients on the lags of inflation sum to one in the Phillips curve. If we do not impose dynamic homogeneity on the VAR's inflation equation, then the differences between the behavior generated by the New Keynesian models and that generated by the VAR become more pronounced (see Dennis, 2003).
} 
plying equation (18) by $\mathbf{M}_{0}$ gives

$$
\mathbf{M}_{0} \mathbf{z}_{t}=\mathbf{m}+\mathbf{M}_{1} \mathbf{z}_{t-1}+\mathbf{v}_{t}
$$

Because $\mathbf{M}_{0}^{\prime-1}$ is upper triangular, $\mathbf{M}_{0}$ is lower triangular and equation (19) is in the form of a recursive VAR. Transformed in this way the impulse responses from the New Keynesian models, generated by shocking $\mathbf{v}_{t}$ not $\mathbf{s}_{t}$, can be compared to those from the benchmark VAR.

To gain some idea of the uncertainty surrounding the benchmark-VAR's impulse responses, resampling methods are used to calculate their 95 percentile range. If the responses from the New Keynesian models lie outside this percentile range, then this indicates that they imply behavior that is atypical for the dataset.

The impulse responses for "demand" and "supply" shocks are shown in Figures 1 and 2. Figure 1 presents the responses for the models with internal habits while Figure 2 presents the responses for the models that have external habits. 
Panel A: Consumption Response

'Demand' Shock

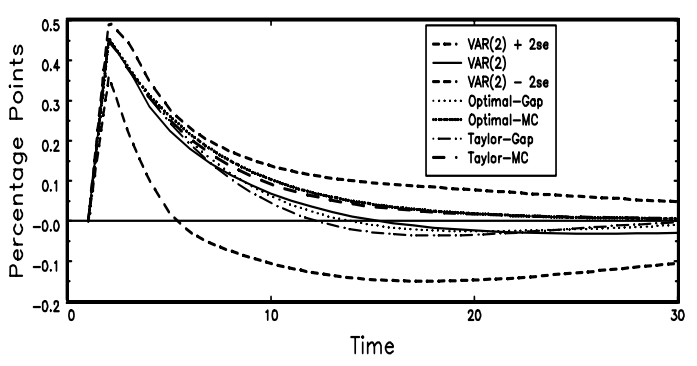

Panel C: Inflation Responses

'Demand' Shock

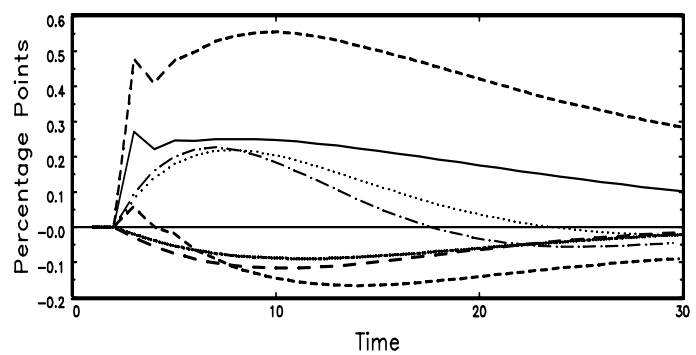

Panel E: Interest Rate Responses 'Demand' Shock

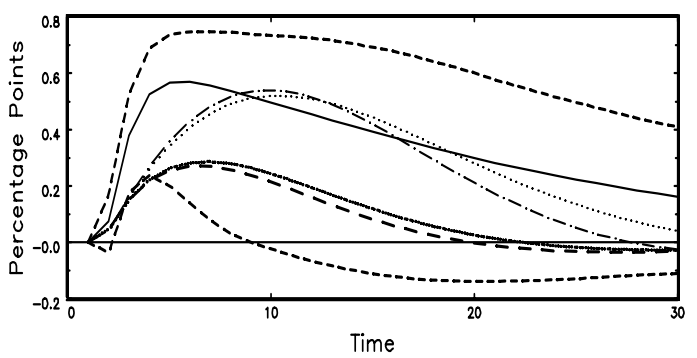

Panel B: Consumption Response

'Supply' Shock

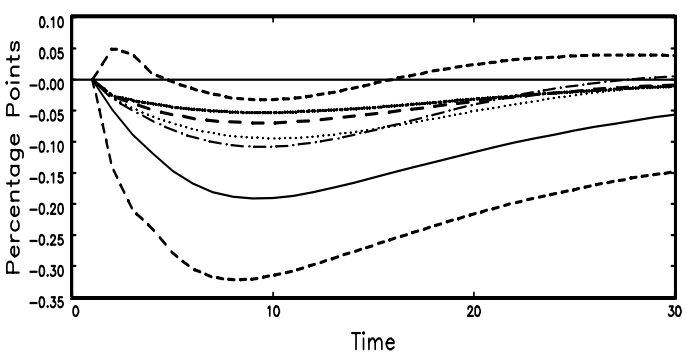

Panel D: Inflation Responses

'Supply' Shock

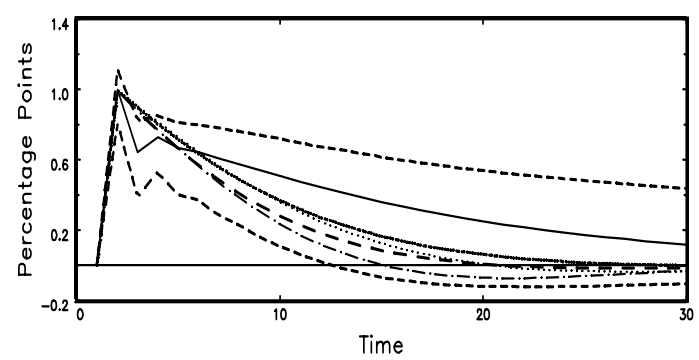

Panel F: Interest Rate Responses 'Supply' Shock

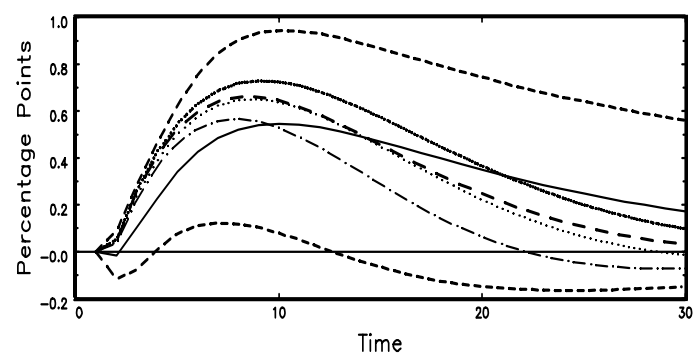

Figure 1: Impulse Responses with Internal Habit Formation

Panels A, C, and E in Figure 1 show how consumption, inflation, and the federal funds rate respond to a one standard deviation demand shock; Panels B, D, and F show how these same variables respond to a one standard deviation supply shock. Where the Phillips curve responds to the gap, the models imply that a demand shock will boost consumption and that this boost in consumption will push up inflation. With higher inflation and a positive gap, policymakers tighten monetary policy, raising the federal funds rate. Similarly, in the face of an adverse supply shock the New Keynesian models predict that inflation will rise causing policymakers to tighten in- 
terest rates. Higher interest rates lead to a drop in consumption as households are induced to defer consumption.

For the specifications that have real marginal costs entering the Phillips curve the implied responses are largely the same, with one important difference. With real marginal costs driving inflation, the demand shock actually causes inflation to fall rather than rise. The reason that inflation falls is that, even though the demand shock leads to higher consumption and a positive gap, the resulting increase in labor supply causes a decline in real wages that offsets the effect on prices of higher demand.

Overall, Figure 1 shows that the responses from the estimated New Keynesian models are in most cases qualitatively consistent with perceived wisdom, with the exception that inflation falls in response to demand shocks when the Phillips curve depends on real marginal costs. However, there are some interesting differences between the responses generated from the New Keynesian models and those generated from the benchmark VAR. In response to a supply shock the New Keynesian models predict an interest rate response by policymakers that is larger than the response generated by the VAR (Panel F), especially soon after the shock's impact. This larger interest rate response may be due to the small estimates of the intertemporal elasticity of substitution in the New Keynesian models. With interest rates having only a small impact on consumption, a larger interest rate movement is required to induce households to defer consumption and produce a negative gap. In the case of a demand shock, the New Keynesian models do reasonably well at replicating the behavior of the VAR, particularly for consumption. However, the New Keynesian models tend to predict that inflation and interest rates will return to baseline more quickly than does the benchmark VAR (Panels C and E).

Turning to the differences between the various New Keynesian models, specifications for which inflation depends on the gap appear to do slightly better at replicating the response of consumption to a supply shock (Panel B). Similarly, these same specifications do a noticeably better job at describing how interest rates and inflation respond to demand shocks. When real marginal costs enter the Phillips curve, a demand shock causes inflation to fall whereas the benchmark VAR predicts that inflation will rise (Panel C). Because inflation falls in response to the demand shock, a much smaller tightening of monetary policy is required to stabilize the economy, so 
the interest rate response for these specifications is much more muted than that from the benchmark VAR (Panel E).

Panel A: Consumption Response 'Demand' Shock

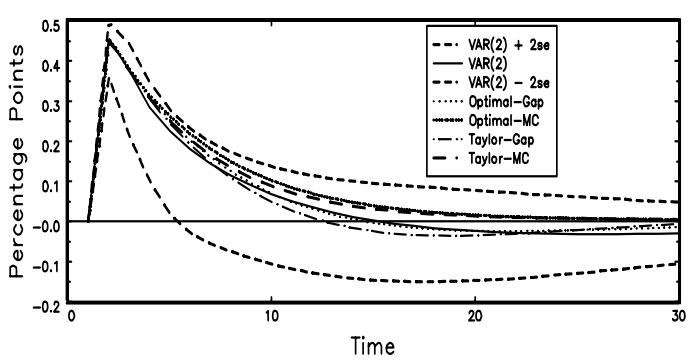

Panel C: Inflation Responses 'Demand' Shock

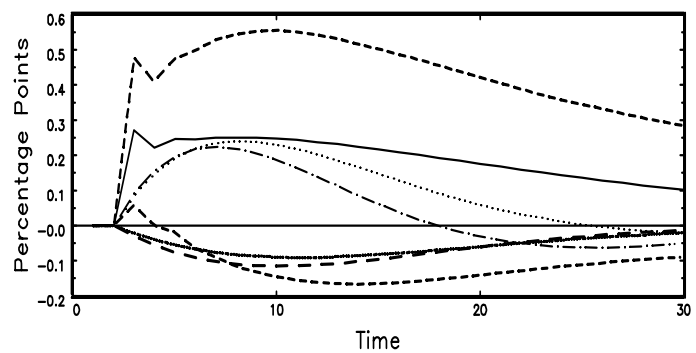

Panel E: Interest Rate Responses 'Demand' Shock

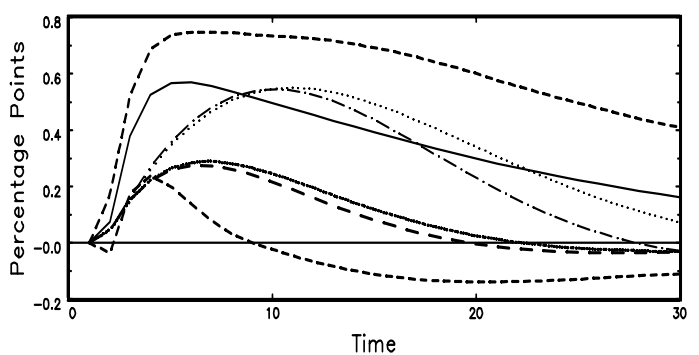

Panel B: Consumption Response 'Supply' Shock

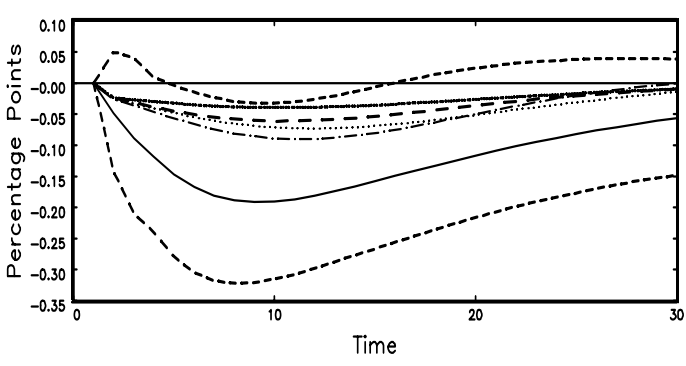

Panel D: Inflation Responses 'Supply' Shock

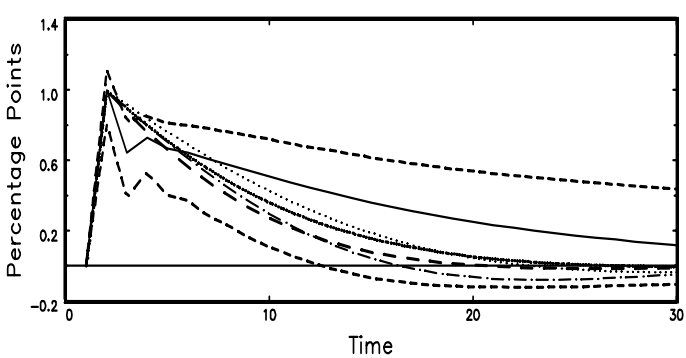

Panel F: Interest Rate Responses 'Supply' Shock

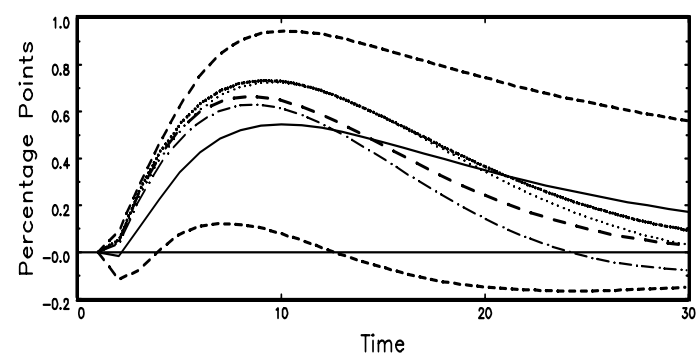

Figure 2: Impulse Responses with External Habit Formation

Figure 2 shows how the models behave when the habit formation is external to the household. In general, the impulse responses are very similar to those generated from internal habits (Figure 1). Again the New Keynesian models predict a larger interest rate response immediately following a supply shock than the benchmark VAR (Panel F), and the models that depends on real marginal costs predict that inflation 
falls following demand shocks (Panel C).

Overall, the close similarities between Figures 1 and 2 demonstrate that internal habits and external habits generate similar behavior, despite the fact that internal habit formation requires households to look two periods into the future when making their consumption choice. Figures 1 and 2 both speak strongly against the specifications that have real marginal costs entering the Phillips curve. It is also worthwhile noting that, as might be expected, the small estimates of the intertemporal elasticity of substitution in the New Keynesian models lead to movements in consumption that are muted relative to the benchmark VAR. The finding that the New Keynesian models are able to accurately account for the response of consumption to a demand shock suggests that a single lag of consumption in the habit formation process is adequate and that generalizing the habit formation process would not significantly improve the models' fit. In fact, when a second lag of consumption is added it is not statistically significant and its coefficient is numerically small. ${ }^{16}$

It seems clear from Figures 1 and 2 that having inflation depend on real marginal costs, while theoretically attractive, leads the models to have undesirable empirical properties. The unusually high estimates of $\xi$ (see Tables 1 and 2) for these specifications are an outcome of the model trying to limit the statistical damage caused by these undesirable properties. But since the key difference between the gap and real marginal costs is that real marginal costs also depends on the lagged gap (see equations 10 and 11), it is apparent that it is this lag of the gap that the data objects to. ${ }^{17}$ Of course the lagged gap term is present because habit formation affects the marginal rate of substitution between consumption and leisure. As a consequence, while it appears important to allow for habit formation when describing consumption behavior, its usefulness for explaining consumption is counterbalanced by the adverse impact it has on the model's ability to explain inflation.

\footnotetext{
${ }^{16}$ This is not the case if the models are estimated on output data rather than on consumption data. Using output data a second lag of the gap in the habit process is statistically significant (but with a negative sign). However, this simply points to the fact that the second lag of output often present in output-based IS curves cannot be attributed to habit formation. If the second lag of the gap were due to habit formation, then it should also be present when the models are estimated on consumption data.

${ }^{17}$ With internal habit formation the expected future gap also affects real marginal costs. However, since the specifications with real marginal costs perform poorly with both internal habits and external habits, it appears likely that is is the lagged gap that is the problem.
} 
We now turn to consider whether internal habits or external habits receive greater support from the data and to whether the data favors optimal discretionary policymaking or the forward-looking Taylor-type rule.

\subsubsection{Internal or External Habits?}

Figures 1 and 2 showed that external habits and internal habits generate very similar impulse response functions. While they produce similar behavior the economics underpinning this behavior is very different. With internal habit formation households are concerned about their own consumption patterns and their marginal utility of consumption is raised when their consumption is high in the pervious period. In contrast, with external habit formation the marginal utility of a household's consumption is raised if other households happened to consume a lot in the previous period.

Unfortunately, because the two models of habit formation are not nested a direct test between them is not possible. An alternative approach is to assess the two approaches using information criteria. Taking this approach, for each specification we construct AIC, BIC, and HQ statistics. ${ }^{18}$ For each assumption about monetary policy and for each assumption about the structure of the Phillips curve, we look at the information criteria with internal habits relative to those with external habits. Values for these relative information statistics that are less than one lend statistical support for internal habits over external habits. The results are presented in Table 3.

\begin{tabular}{l|llll}
\hline \hline \multicolumn{5}{l}{ Table 3: Internal-habits relative to external-habits } \\
\hline \hline Criterion & OP-Gap & OP-MC & T-Gap & T-MC \\
\hline AIC & 0.998 & 1.000 & 0.998 & 1.000 \\
BIC & 0.998 & 1.000 & 0.998 & 1.000 \\
HQ & 0.998 & 1.000 & 0.998 & 1.000 \\
\hline \hline
\end{tabular}

Of course, these information criteria are affected by all aspects of a model, not only whether it has internal or external habits. However, Table 3 shows that all of these relative information criteria are less than or equal to one. The differences from one are small, but systematic. ${ }^{19}$ According to these relative information statistics,

\footnotetext{
${ }^{18}$ See the papers by Akiake (1973), Schwarz (1978), and Hannan and Quinn (1979), respectively.

${ }^{19}$ All of the relative information statistics are actually less than one, but those for the marginal-cost specifications only differ from one at the fourth decimal place.
} 
then, a slightly better fit is obtained from specifications that have internal habits. That the statistical differences are modest is in some sense not too surprising, especially given the similarities between Figures 1 and 2. If the differences were large, then the macroeconomics literature would probably have adopted one approach over the other. Nevertheless, the slight differences that there are favor internal habits. ${ }^{20}$

\subsubsection{Optimal Discretionary Policy or a Taylor-type Rule?}

While it is often convenient to simply specify an instrument rule for monetary policy, there are important advantages to treating policymakers as optimizing agents. Provided that the models are estimated as a system, both approaches allow one to estimate an implicit inflation target and they both produce decision rules that depend on the same set of state variables. ${ }^{21}$ Where the two approaches differ is that assuming policy is set optimally allows us to estimate the parameters that enter the policy objective function, which are "deeper" than the feedback parameters in a central bank's decision rule. Statistical inference on these policy objective function parameters can then be performed.

Setting aside these differences, it is valuable to assess the two approaches purely on statistical grounds. However, like when comparing internal to external habits, the two descriptions of policy are not nested and a direct test between them is not possible. However, taken as systems, the two approaches to policy impose restrictions on the models' equilibrium behavior and the data may support one set of restrictions over the other. To compare the two approaches, we construct relative information criteria. Relative information criteria that are less than one indicate support for a Taylor-type rule over an optimal discretionary rule. The results are shown in Table 4.

\footnotetext{
${ }^{20}$ It is worth noting that this conclusion does not extend to the case where the models are estimated on output data. Dennis (2004) finds, using a range of measures of the output/consumption gap, that when output data is used external habits fit the data slightly better than internal habits.

${ }^{21}$ The assumption that monetary policy is set optimally leads naturally to system-estimation. Instrument rules can often be estimated in isolation (provided valid instruments can be found), but this approach does not allow $\pi^{*}$ to be estimated.
} 


\begin{tabular}{l|llll}
\hline \hline \multicolumn{5}{c}{ Table 4: Taylor-type rule relative to optimal discretionary policy } \\
\hline \hline Criterion & Internal-Gap & Internal-MC & External-Gap & External-MC \\
\hline AIC & 1.002 & 1.003 & 1.002 & 1.003 \\
BIC & 1.007 & 1.007 & 1.006 & 1.007 \\
HQ & 1.004 & 1.005 & 1.004 & 1.004 \\
\hline \hline
\end{tabular}

Table 4 reveals that regardless of the information criteria used, regardless of how habit formation is modeled, and regardless of whether the Phillips curve depends on real marginal costs or on the gap, a slight improvement is offered when monetary policy is modeled using an optimal discretionary rule. The improvements are modest, however, which suggests that describing monetary policy in terms of a Taylor-type rule will lead to very little loss of performance. ${ }^{22}$ This result is surprising as the emphasis the literature places on simple instrument rules might suggest that optimal policy rules are rejected in favor of Taylor-type rules. Table 4 shows clearly that this is not the case. Thus, not only do optimal discretionary rules allow us to estimate and perform inference on a central bank's policy objective function, they also appear to describe US data as well as or better than Taylor-type rules do.

\section{Conclusion}

New Keynesian models are widely used to examine issues and questions related to monetary policy and the dynamic effects of shocks. The strength of these models lies in their being micro-founded, which, together with their simplicity, leads to behavior and propagation mechanisms are easily understood. Because the propagation mechanisms are transparent, the results that emerge generally have a clear intuition. But if the policy implications that emerge from these models are to be taken seriously, then it is important for the models to also be well grounded from an empirical standpoint. Yet, optimal policy rules are often calculated and analyzed using models that are "calibrated", and when these models are taken to the data attention has generally focused on individual equations, such as the Phillips curve or the policy rule, and not on the system as a whole.

\footnotetext{
${ }^{22}$ The Taylor-type rule specifications contain one additional parameter than the optimal discretionary rule specifications. Tables 1 and 2 show that the value of the log-likelihood is lower for the Taylor-type rule specifications, making it clear that it is the penality applied to parameter-number that tilts the relative information criteria in favor of optimal discretionary policymaking.
} 
This paper looks at the empirical properties of several popular New Keynesian models in an effort to better understand which specifications and which modelcharacteristics receive the most support from the data. In some specifications monetary policy is set according to a Taylor-type rule, in others according to an optimal discretionary rule. All specifications had habit formation in consumption, but some specifications had internal habits, others external habits. On the supply side, the Phillips curve was allowed to depend alternatively on the gap or real marginal costs; the relationships between these specifications, and the implications habit formation have for real marginal costs, were shown and discussed. Each specification was formulated and estimated as a system.

In all, eight specifications were estimated. To assess their properties and behavior, these eight specifications were considered in terms of their parameter estimates, their impulse response functions, and their overall ability to summarize the data, as quantified through standard information criteria. Several interesting and important results emerged. First, the parameter estimates suggest that there is very little curvature in the utility function with respect to consumption relative to habit, leading to small estimates of the intertemporal elasticity of substitution. This finding was robust across the specifications considered and is broadly consistent with the implications of other studies.

Second, specifications that had the Phillips curve depend on real marginal costs were not well received by the data. For those specifications the estimates of the Calvo-pricing parameter were very high at 0.97 , implying that only 3 percent of firms adjust their price each quarter, regardless of how monetary policy and habit formation are modeled. Not only are these estimates of the Calvo-pricing parameter implausibly high, these specifications produced impulse response functions that had inflation falling in response to demand shocks. While such falls in inflation can be rationalized in terms of the micro-theory, these responses are significantly different to those generated from a benchmark VAR model. When the Phillips curve depends on the gap, estimates of the Calvo-pricing parameter are about 0.75 , very similar to other estimates in the literature, and the impulse response functions are qualitatively similar to those from the benchmark VAR. The data, therefore, appear to favor specifications that have the gap, rather than real marginal costs, in the Phillips 
curve.

Third, in terms of their fit the data, relatively little hinges on how habit formation is modeled. Internal habit formation and external habit formation produced similar consumption behavior; the impulse response functions that emerged from the respective equilibriums were very similar to each other and to the responses from the benchmark VAR. Using standard information criteria to compare models with internal habits to those with external habits, the data slightly (but systematically) favor specifications that have internal habits.

Finally, modeling the monetary policy formulation process in terms of a constrained optimization problem leads to policy behavior and to impulse response functions that were similar to an estimated forward-looking Taylor-type rule. Moreover, the relative information criteria slightly favored specifications that had optimal policymaking, demonstrating that optimal policy behavior need not be detrimental to model-fit. Looking at the estimates of the policy objective functions, they show evidence for interest rate smoothing, but not for consumption stabilization. The low weight on consumption stabilization is consistent with the implications of secondorder utility approximations, but not with flexible inflation targeting.

The specifications estimated in this paper are still reasonably simple and it would be desirable to extend them so that their implications for a broader set of variables can be assessed. In particular, the poor performance of the specifications that contain real marginal costs appears to be a consequence of the effect habit formation has on the marginal rate of substitution between consumption and leisure. It is possible, then, that a more thorough treatment of the labor market, aimed at better capturing the relationship between real wages and this marginal rate of substitution, may overcome some of the difficulties that these specifications face. One approach would be to introduce a nominal wage rigidity, perhaps along the lines of Erceg et al., (2000). It would, of course, also be desirable to generalize the economy's production technology to allow for physical capital as a productive input, perhaps building on the framework developed in Christiano et al., (2004), but retaining the assumption that policymakers behave optimally, which appears to be a useful way of summarizing monetary policy behavior. These are issues to be addressed in future work. 


\section{References}

[1] Akaike, A., (1973), "Information Theory and the Extension of the Maximum Likelihood Principle," in Petrov, B., and Csaki, F., (eds) 2nd International Symposium on Information Theory, Akailseoniai-Kiudo, Budapest, pp267-281.

[2] Amato, J., and T. Laubach, (2004), "Implications of Habit Formation for Optimal Monetary Policy," Journal of Monetary Economics, 51, pp305-325.

[3] Ball, L., (1991), "The Genesis of Inflation and the Costs of Disinflation," Journal of Money, Credit and Banking, 23, 3, pp439-451.

[4] Blanchard, O., (1981), "What is Left of the Multiplier Accelerator?" American Economic Review Papers and Proceedings, 71, 2, pp150-154.

[5] Boldrin, M., Christiano, L., and J. Fisher, (2001), "Habit Persistence, Asset Returns, and the Business Cycle," American Economic Review, 91, 1, pp149166.

[6] Buiter, W., and I. Jewitt, (1981), "Staggered Wage Setting with Real Wage Relativities: Variations on a Theme of Taylor," Manchester School of Economic and Social Studies, 49, 3, pp211-228.

[7] Calvo, G., (1983), "Staggered Contracts in a Utility-Maximising Framework," Journal of Monetary Economics, 12, pp383-398.

[8] Castelnuovo, E., and P. Surico, (2004), "Model Uncertainty, Optimal Monetary Policy and the Preferences of the Fed," Scottish Journal of Political Economy, 51,1 , pp105-126.

[9] Campbell, H., and J. Cochrane, (1999), "By Force of Habit: A ConsumptionBased Explanation of Aggregate Stock Market Behavior," Journal of Political Economy, 107, 2, pp205-251.

[10] Campbell, J., and G. Mankiw, (1989), "Consumption, Income, and Interest Rates: Reinterpreting the Time Series Evidence," in Blanchard, O., and S. Fischer, (eds) NBER Macroeconomics Annual 1989, MIT Press, Cambridge.

[11] Cho, S., and A. Moreno, (2004), "A Small-Sample Study of the New-Keynesian Macro Model," Columbia University, mimeo.

[12] Chow, G., (1981), "Estimation of Rational Expectations Models," Chapter 16, Econometric Analysis by Control Methods, John Wiley and Sons, New York.

[13] Christiano, L., Eichenbaum, M., and C. Evans, (2004), "Nominal Rigidities and the Dynamic Effects of a Shock to Monetary Policy," Journal of Political Economy, forthcoming.

[14] Clarida, R., Galí, J., and M. Gertler, (1999), "The Science of Monetary Policy: A New Keynesian Perspective," Journal of Economic Literature, 37, 4, pp16611707.

[15] Clarida, R., Galí, J., and M. Gertler, (2000), "Monetary Policy Rules and Macroeconomic Stability: Evidence and Some Theory," The Quarterly Journal of Economics, February, pp147-180.

[16] Collins, S., and P. Siklos, (2001), "Optimal Reaction Functions, Taylor's Rule and Inflation Targets: The Experiences of Dollar Bloc Countries," Wilfrid Laurier University mimeo. 
[17] Dennis, R., (2003), "New Keynesian Optimal-Policy Models: An Empirical Assessment," Federal Reserve Bank of San Francisco Working Paper \#2003-16 (November, 2004)

[18] Dennis, R., (2004), "Inferring Policy Objectives from Economic Outcomes," $O x$ ford Bulletin of Economics and Statistics, 66, pp735-764.

[19] Duffy, J., and P. McNelis, (2001), "Approximating and Simulating the Stochastic Growth Model: Parameterized Expectations, Neural Networks, and the Genetic Algorithm," Journal of Economic Dynamics and Control, 25, pp1273-1303.

[20] Edge, R., Laubach, T., and J. Williams, (2003), "The Responses of Wages and Prices to Technology Shocks," Federal Reserve Bank of San Francisco Working Paper \#2003-21 (December, 2003).

[21] Erceg, C., Henderson, D., and A. Levin, (2000), "Optimal Monetary Policy with Staggered Wage and Price Contracts," Journal of Monetary Economics, 46, pp281-313.

[22] Evans, G., and S. Honkapohja, (2001), Learning and Expectations in Macroeconomics, Princeton University Press, Princeton, New Jersey

[23] Fuhrer, J., (1997), "The (Un)importance of Forward-Looking Behavior in Price Specifications," Journal of Money, Credit, and Banking, 29, 3, pp338-350.

[24] Fuhrer, J., (2000), "Optimal Monetary Policy in a Model with Habit Formation," American Economic Review, 90, 3, pp367-390.

[25] Fuhrer, J., and G. Moore, (1995), "Inflation Persistence," The Quarterly Journal of Economics, 110, 1, pp127-159.

[26] Favero, C., and R. Rovelli, (2003), "Macroeconomic Stability and the Preferences of the Fed. A Formal Analysis, 1961-98," Journal of Money, Credit, and Banking, $35, \mathrm{pp} 545-556$.

[27] Galí, J., and M. Gertler, (1999), "Inflation Dynamics: A Structural Econometric Analysis," Journal of Monetary Economics, 44, pp195-222.

[28] Giannoni, M., and M. Woodford, (2003), "Optimal Inflation Targeting Rules," in Bernanke B., and M. Woodford (eds), Inflation Targeting, University of Chicago Press, Chicago.

[29] Hall, R., (1988), "Intertemporal Substitution in Consumption," Journal of Political Economy, 96, 2, pp339-357.

[30] Hall, R., and J. Taylor, (1997), Macroeconomics, Fifth Edition, W. W. Norton and Company, New York.

[31] Hannan, E., and B. Quinn, (1979), "The Determination of the Order of an Autoregression," Journal of the Royal Economic Society, Series B, 41, pp190195.

[32] Ireland, P., (1997), "A Small, Structural, Quarterly Model for Monetary Policy Evaluation," Carnegie-Rochester Conference Series on Public Policy, 47, pp83108.

[33] Kim, J., (2000), "Constructing and Estimating a Realistic Optimizing Model of Monetary Policy," Journal of Monetary Economics, 45, pp329-359. 
[34] McCallum, B., and E. Nelson, (1999), "Nominal Income Targeting in an OpenEconomy Optimizing Model," Journal of Monetary Economics, 43, pp553-578.

[35] Roberts, J., (1997), "Is Inflation Sticky?" Journal of Monetary Economics, 39, pp173-196.

[36] Rogoff, K., (1985), "The Optimal Degree of Commitment to an Intermediate Monetary Target," The Quarterly Journal of Economics, 100, 4, pp1169-1189.

[37] Rotemberg, J., and M. Woodford, (1997), "An Optimization-Based Econometric Framework for the Evaluation of Monetary Policy," in Bernanke, B., and J. Rotemberg, (eds) NBER Macroeconomics Annual 1997, MIT Press, Cambridge.

[38] Rudd, J., and C. Whelan, (2003), "Can Rational Expectations Sticky-Price Models Explain Inflation Dynamics?" Board of Governors of the Federal Reserve System, mimeo (February, 2003).

[39] Salemi, M., (1995), "Revealed Preferences of the Federal Reserve: Using Inverse Control Theory to Interpret the Policy Equation of a Vector Autoregression," Journal of Business and Economic Statistics, 13, pp419-433.

[40] Sbordone, A., (2002), "Prices and Unit Labor Costs: A New Test of Price Stickiness," Journal of Monetary Economics, 49, pp265-292.

[41] Schwarz, G., (1978), "Estimating the Dimension of a Model," Annals of Statistics, 6, pp461-464.

[42] Sims, C., and T. Zha, (2001), "Macroeconomic Switching," Princeton University mimeo.

[43] Smets, F., (2003), "Maintaining Price Stability: How Long is the Medium Term?" Journal of Monetary Economics, 50, pp1293-1309.

[44] Smets, F., and R. Wouters, (2003), "An Estimated Stochastic Dynamic General Equilibrium Model of the Euro Area," Journal of the European Economic Association, 1, 5, pp1123-1175.

[45] Söderlind, P., (1999), "Solution and Estimation of RE Macromodels with Optimal Policy," European Economic Review, 43, pp813-823.

[46] Söderlind, P., Söderström, U., and A. Vredin, (2003), "New Keynesian Models and Monetary Policy: A Re-Examination of the Stylized facts" Sveriges Riksbank Working Paper (August, 2003).

[47] Taylor, J., (1999), Monetary Policy Rules, University of Chicago Press, Chicago.

[48] Woodford, M., (2003), Interest and Prices, Princeton University Press, Princeton, New Jersey.

[49] Yun, T., (1996), "Nominal Price Rigidity, Money Supply Endogeneity, and Business Cycles," Journal of Monetary Economics, 37, pp345-370. 